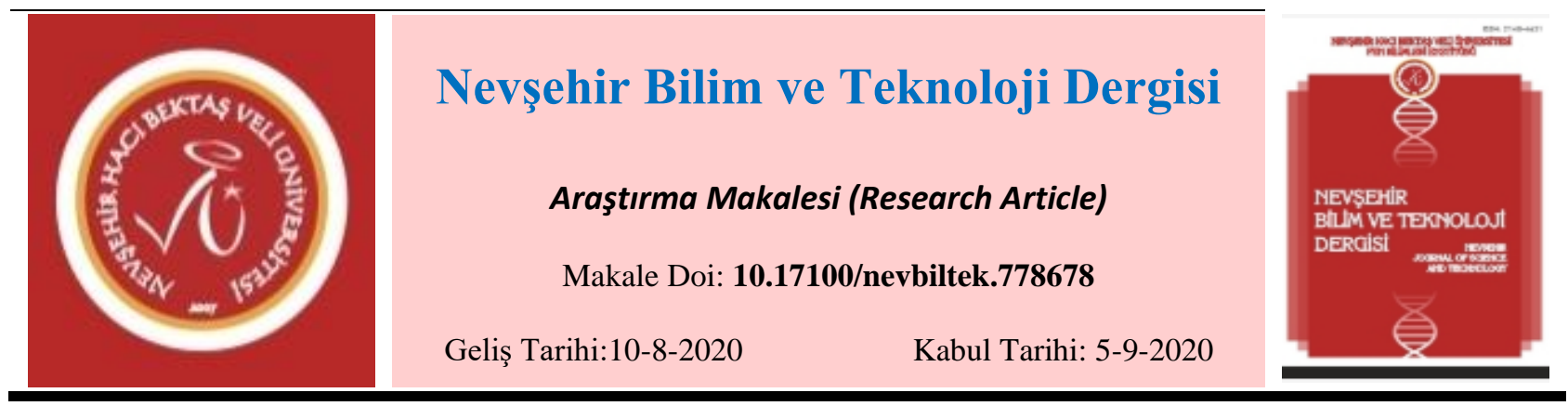

\title{
Raman Spektroskopisinin İlkeleri ve Mineral Tanımlamalarında Kullanılması
}

\author{
Musa Avni AKÇE ${ }^{1 *}$, Yusuf Kağan KADIOĞLU ${ }^{2,3}$ \\ ${ }^{1}$ Nevşehir Hacı Bektaş Veli Üniversitesi, Mühendislik-Mimarlık Fakültesi, Jeoloji Müh. Bölümü, 50300 Nevşehir \\ ORCID ID: 0000-0002-9180-7015 \\ ${ }^{2}$ Ankara Üniversitesi, Mühendislik Fakültesi, Jeoloji Müh. Bölümü, 06830 Ankara, \\ ${ }^{3}$ Ankara Üniversitesi, Yer Bilimleri Uygulama ve Araştırma Merkezi (YEBİM), 06830 Ankara \\ ORCID ID: 0000-0002-7894-2220
}

$\ddot{\mathbf{O z}}$

Minerallerin ayrıntılı olarak adlandırmaları ve tanımlamaları ince kesit üzerinde polarizan mikroskop yardımı ile ve toz hale getirilerek X-Işını Kırınımı (XRD) yöntemi ile yapılabilmektedir. Her iki yöntemde mineraller üzerinde tahribat yapılmakta ve ciddi bir bilgi birikimi ve deneyim gerektirmektedir. Raman spektroskopisinde örnek üzerinde herhangi bir tahribat yapmadan, mineral üzerine gönderilerek molekül ile etkileşime giren ışı̆̆ın dalga boyuna göre saçılan 1șı̆ğı dalga boyundaki farklar sonucu olușan spektrumlar, mineralin kimliğini yansıtabilmektedir. Her mineralin moleküler bileșim farklılığından oluşan spektrumlar yardımıyla mineral içerisindeki değişimler ölçülebilmektedir. Böylece mineral adlandırmanın yanında taze ve bozunmuş mineral farklılıkları da bu yöntem ile ayırt edilmektedir. Bu çalışmada Raman spektroskopi yöntemini kullanarak plajiyoklaz, ortoklaz, anortoklaz, biyotit, filogopit ve granat minerallerinin Raman spektroskopik tanımlanmaları yapılmış ve oluştukları kayanın kökeni hakkında yorumlar yapılmıştır. Böylece minerallerin tahribatsız analiz yöntemi ile türlerinin tespiti örneklerle ortaya konulmuştur.

Anahtar Kelimeler: Raman Spektroskopisi, Dalga boyu, Mineraloji, Analiz yöntemi.

\section{Principles of Raman Spectroscopy and Their Uses in the Determination of the Minerals}

\begin{abstract}
The detailed nomenclature and descriptions of the minerals can be made with the aid of a polarizing microscope on the thin section and by powdering with the X-Ray Diffraction (XRD) method. In both methods, minerals are damaged and require serious knowledge and experience. In Raman spectroscopy without any destruction of the sample, the spectra formed as a result of differences in the wavelength of the scattered light compared to the wavelength of the light that interacts with the molecule by being sent on the mineral can reflect the identity of the mineral. The spectra, which consist of the molecular composition difference of each mineral, can also reflect the changes of the measured mineral. Furthermore, in addition to mineral naming, fresh and altered mineral differences are also distinguished by this method. In this study, Raman spectroscopic definitions of plagioclase, orthoclase, anorthoclase, biotite, phlogopite and garnet minerals were made using the Raman spectroscopy method and comments were made on the origin of the rock from which they were formed. Thus, the determination of the types of minerals by non-destructive analysis method has been demonstrated with examples.
\end{abstract}

Keywords: Raman Spectroscopy, Wavelength, Mineralogy, Analysis method.

\section{Giriş}

Raman spektroskopisi, bir titreşim spektroskopi türüdür. Raman spektroskopisinin temelini Raman saçılmas1 oluşturmaktadır. Raman saçılması yani inelastik saçılma, ilk defa ünlü Hint fizikçi Sir Chandrasekhara Venkata Raman (1888-1970) tarafından 1928'de keşfedilmiş ve bu buluşu kendisine 1930'da Nobel Fizik Ödülü’nü kazandırmıştır. Bundan sonra da "Raman Saçılması" şeklinde kendi adıyla literatüre geçmiştir.

Raman saçılması, moleküllerin kimyasal yapısı hakkında önemli bilgiler vermektedir. Bir molekülün titreşimsel spektrumu, o molekülün imzası veya "moleküler parmak izi” özelliği olarak düşünülebilir. Raman spektroskopisi, bir numunenin görünür bölge veya yakın-infrared monokromatik ışından oluşan güçlü bir lazer kaynağıyla ışınlanmasıyla saçılan ışının belirli bir açıdan ölçümüne dayanır [1]. Raman saçılması sırasında saçılan ışı̆̆ın enerjisinde molekül ile 
Nevşehir Bilim ve Teknoloji Dergisi (2020), 9(2) 99-115

etkileşen ışığınkine göre bir fazlalık veya azlık oluşur. Oluşan bu fazlalık veya azlık, 1şıkla etkileşen molekülün titreşim enerji düzeyleri arasındaki enerji farkları kadardır. Bu sebeple Raman saçılmasının spektroskopik incelenmesi ile moleküllerin titreşim enerji düzeyleri hakkında bilgi edinilebilmekte ve bu spektroskopik yöntem Raman spektroskopisi adını almaktadır. Molekül ile etkileşen ışığın dalga boyuna göre saçılan ışığın dalga boyunda oluşan farklar Raman kayması (Raman shift) olarak adlandırılır.

Raman spektrometreleri ışı (lazer) kaynağı, numune aydınlatma sistemi ve spektrometre olmak üzere üç ana bileşenden oluşmaktadır. Konfokal Raman spektrometresi ise konfokal mikroskop ve hassas Raman spektrometresinin birleşiminden oluşan bir sistemdir. Bu sistemle yalnızca Raman spektrumları değil aynı zamanda çok hızlı bir şekilde Raman görüntüleri elde edilebilmektedir [2].

Raman spektroskopisi; inorganik ve organik sistemlerin hem kalitatif (nitel) hem de kantitatif (nicel) analizinde kullanılabilen hızlı, kolay, örneği tahrip etmeden uygulanabilen çok önemli bir spektroskopik yöntemdir. Raman, IR'nin tamamlayıcısı olup IR'de gözlenmeyen zayıf titreşimler burada gözlenebilmektedir [1]. Kimyadan tıpa, biyolojiye, arkeolojiye, malzeme bilimine, ilaç ve kâğıt endüstrisine kadar birçok uygulama alanına sahip Raman spektroskopisi son yıllarda jeoloji alanında da kullanılmaya başlamıştır. Mineralojik incelemelerde özellikle mineral tayinine yönelik olarak kullanılan bu yöntemle çok doğru ve başarılı sonuçlar elde edilmektedir [3, 4]. Minerallerin Raman spektrumlarının; polarizan mikroskop incelemeleri, XRD ve kimyasal analizlerle elde edilen bileşimleri ile karşılaştırıldığında birbirleriyle çok uyumlu ve doğru sonuçlar verdikleri görülmektedir. Konfokal Raman Spektroskopisi; mineralojik ve petrolojik çalışmalarda optik mikroskop, kimyasal analiz ve diğer spektroskopik incelemeleri desteklemekte ve tamamlamaktadır. Hatta bazı durumlarda rutin optik mikroskop incelemesi, XRD ve elektron mikroprob gibi ileri analitik yöntemlerle dahi belirlenemeyen mineraller Raman spektroskopisi ile türlerine kadar hassas bir şekilde tayin edilebilmektedir. Raman incelemelerinde numune hazırlama işleminin zahmetsiz olması, küçük numunelerin dar bir alanında bile ölçüm yapılabilmesi, ölçüm zamanının kısa olması ve kullanım kolaylı̆̆ı vb. gibi avantajları da bu yöntemin mineralojik uygulamalarda daha çok tercih edilmesine ve giderek yaygınlaşmasına neden olmuştur. Ayrıca tahribatsız analiz kabiliyetine sahip olması nedeniyle süs taşlarının tanımlanmasında da tartışmasız bir analiz yöntemi olmuştur.

Magmatik, metamorfik ve sedimanter kayalarda yer alabilen farklı mineral ve mineral gruplarının Raman spektroskopik özellikleri ve karakteristikleri üzerine yaklaşık 1980'li yılların sonundan itibaren muhtelif çalışmalar yapılmaya başlamıştır. Raman spektroskopisinin doğrudan granitoyid kayalarında uygulanmasına yönelik çalışmalar ise 1990’lı yılların sonunda başlamış ve günümüze kadar devam etmektedir. Granitoyidler üzerine yapılan Raman çalışmalarında genellikle sıvı kapanımlar konusunda çalışılmıştır. Son yıllarda özellikle ülkemizde, granitoyidlerde yer alan minerallerin Raman spektrumları kullanılarak magmanın kristalleşme süreçlerindeki değişimler üzerine spesifik çalışmalar yapılmıştır [5-17]. Ülkemizde mineraloji alanında yapılan Raman spektroskopik çalışmalarında çoğunlukla magmatik kayalar içindeki mineraller incelenmiş olmakla birlikte metamorfik kayalardaki minerallerin spektroskopik özellikleri üzerine de çalışma yapılmıştır [18].

Bu çalışma kapsamında; Yozgat İntrüzif Kompleksi (YİK) granitoyid kayalarından ve Orta Anadolu'nun metamorfik temelinden, Raman spektrumlarının korelasyonu ve kristalleşmeleri sırasındaki oluşumlarını irdelemek için alınmış plajiyoklaz, ortoklaz, anortoklaz, biyotit, filogopit ve granat mineralleri üzerinde analizler yapılmıştır. Bu minerallerin Raman spektrum sonuçları kullanılarak magmanın kristalleşme süreçlerindeki farklılıklar da görülmeye çalışılmış ve Raman spektroskopisinin önemi ortaya konulmuştur.

\section{Materyal ve Metot}

$\mathrm{Bu}$ çalı̧̧ada Raman spektroskopisine dayanarak, minerallerin Raman kayma özellikleri kullanılarak minerallerin tanımlanma ve adlandırmaları yapılmıștır. Bu amaçla Orta Anadolu Kristalen Karmaşı̆̆ı (OAKK) 
Nevşehir Bilim ve Teknoloji Dergisi (2020), 9(2) 99-115

içerisindeki magmatik ve metamorfik kayalardan alınan feldispat, biyotit ve granat minerallerinin Raman spektroskopik karakteristikleri incelenerek tanımlanmıştır.

Öncelikle çalışma alanından alınmış kaya örneklerinin üstü açık parlak ince kesitleri yaptırılmıştır. Bu ince kesitler Ankara Üniversitesi Jeoloji Mühendisliği Bölümü Petrografi Araştırma Laboratuvarı'nda “LEICA DMLP” model polarizan mikroskop kullanılarak petrografik açıdan incelenmiştir. Konfokal Raman Spektrometresinde incelenecek mineraller belirlenmiş ve ince kesit üzerinde yerleri işaretlenmiştir.

Raman spektroskopisi çalışmaları, Ankara Üniversitesi Yer Bilimleri Uygulama ve Araştırma Merkezi (YEBİM) Laboratuvarı'nda yüksek çözünürlüklü ve analitik konfokal mikroskoplu "HORIBA Jobin Yvon LabRAM HR" model konfokal Raman spektrometresi kullanılarak yapılmıştır. Kullanılan bu konfokal Raman spektrometre cihazı $633 \mathrm{~nm}$ dalga boyunda lazer seti ile donatılmış olup CCD dedektör kullanılarak spektrumlar elde edilmiştir. Kaydedilen spektrumlar, Gaussian/Lorentzian karma fonksiyonları kullanılarak LabSpec 4.02 (HORIBA Jobin Yvon) yazılımı ile incelenmiştir.

\subsection{Raman Spektroskopisi Hakkinda Genel Bilgiler}

Moleküllerin şiddetli bir monokromatik ışın demeti ile etkileşmesi sırasında 1şık absorpsiyonu olayı gerçekleşmiyorsa 1şık saçılması olayı meydana gelebilmektedir. 1928 yılında Hint fizikçi C.V. Raman, belirli moleküllerce saçılan ışının ufak bir kesrinin görünür alandaki dalga boyunun gelen ışlğınkinden farklı olduğunu ve buna ilaveten dalga boyundaki kaymaların, saçılmadan sorumlu moleküllerin kimyasal yapısına bağglı olduğunu bulmuştur [1]. İlk defa C.V. Raman tarafından bulunan bu saçılma olayı kendi adıyla "Raman saçılması" şeklinde anılmaya başlanmıştır.

Raman spektroskopisi, bir numunenin genellikle görünür bölge veya yakın-IR bölge monokromatik ışından oluşan güçlü bir lazer kaynağıyla ışınlanmasıyla saçılan ışının, belirli bir açıdan ölçümüne dayanır. Işıı saçılması sırasında saçılan ışığın büyük bir kısmının enerjisi madde ile etkileşen ışığın enerjisine eşit olur, bu tür elastik saçılma olayına Rayleigh saçılması denir. Elastik saçılma olayının yanı sıra, saçılan ışığın çok az bir kısmı ise molekül ile etkileşmeye giren ışı̆̆ın enerjisinden daha farklı enerjilerle saçılır. Bu tür elastik olmayan (inelastik) saçılma olayı ise Raman saçılması adını alır (Şekil 1).

Rayleigh saçılmasında;

saçılan ışığın dalga boyu = gelen ışığın dalga boyu

Raman saçılmasında ise;

saçılan 1şı̆̆ın dalga boyu > gelen ışığın dalga boyu ya da saçılan ışığın dalga boyu < gelen 1şığın dalga boyu

şeklindedir (Şekil 1).

Rayleigh saçılması olayında Raman saçılmasına göre $10^{4}-10^{5} \mathrm{kez}$ daha şiddetli bir saçılmış ışık oluşur. Ancak Rayleigh saçılması tek bir pik verir ve titreşim geçişleri hakkında bilgi vermez. Raman saçılması sırasında saçılan ışığın enerjisinde molekül ile etkileşen 1şığınkine göre oluşan fazlalık veya azlık, 1şıkla etkileşen molekülün titreşim enerji düzeyleri arasındaki enerji farkları kadardır. Bu nedenle de Raman saçılmasının spektroskopik incelenmesi ile moleküllerin titreşim enerji düzeyleri hakkında bilgi edinilebilir [19]. Bu spektroskopik yöntem Raman spektroskopisi olarak adlandırılır. Moleküller ile etkileştirilen ışığın kaynağı olarak genellikle lazer türü kaynaklar kullanıldığından bu yönteme Lazer Raman Spektroskopisi adı da verilmiştir. 


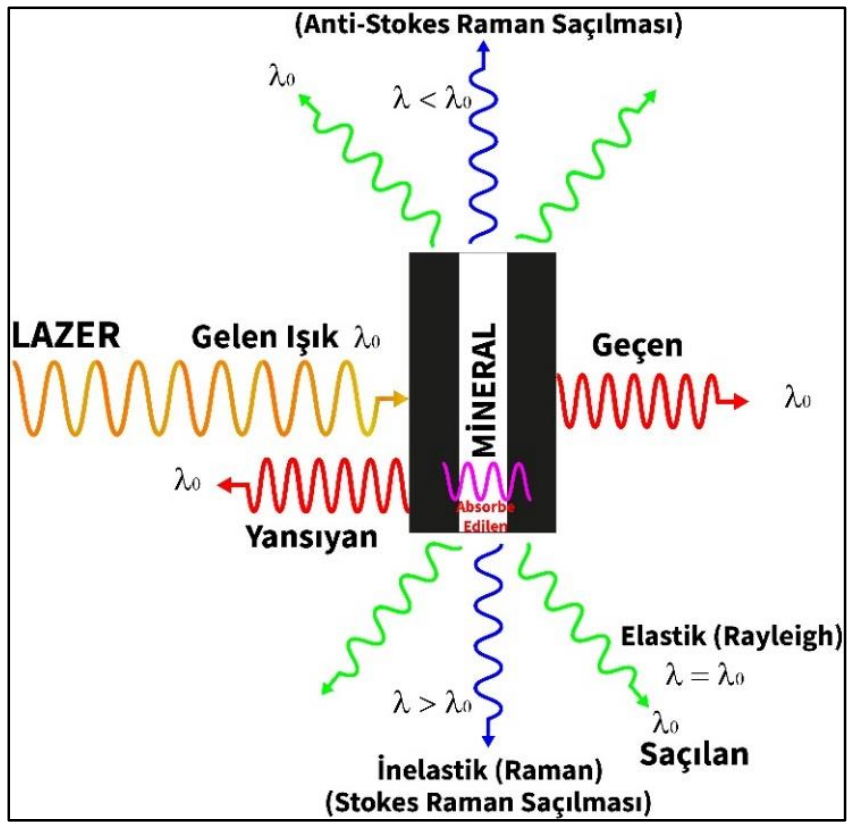

Şekil 1. Mineral üzerinde Rayleigh ve Raman saçılmalarının optik davranışları

Raman spektroskopisinde molekül ile etkileşen 1şığın dalga boyuna göre saçılan ışığın dalga boyunda oluşan farklar ölçülür. Bu farklar Raman kayması olarak adlandırılır. Raman saçılması ile moleküllerin kimyasal yapısı hakkında önemli bilgiler elde edilebilmekte, gaz, sıvı ve katı örnekler incelenebilmektedir. Uyarım (excitation) için bir lazer kaynağı kullanılmaktadır. Rayleigh saçılması güçlü ve gelen ışınla aynı frekansa $\left(v_{0}\right)$ sahip iken Raman saçılması ise çok zayıf (gelen 1şııın $\sim 10^{-5}$ 'i) ve $v_{0} \pm v_{m}$ frekanslarına sahiptir ( $v_{m}$ : bir molekülün titreşim frekansıdır). $v_{0}-v_{m}$ ve $v_{0}+v_{m}$ hatlarına sırasıyla Stokes ve anti-Stokes hatları denilir [2]. Stokes türü saçılma hatları Rayleigh saçılma hattına göre negatif $\Delta v$ değerlerinde gözlenirken anti-Stokes türü saçılma hatları ise pozitif $\Delta v$ değerlerinde gözlenirler. Bir molekülde gözlenen Raman hatlarının mutlak $\Delta v$ değerleri hattın Stokes veya anti-Stokes türü olmasına bağlı değildir ve her iki durumda da aynıdır [19]. Dalga boyu $488.0 \mathrm{~nm}$ olan lazer ışınlarıyla uyarılıış $\mathrm{CCl}_{4}$ 'ün Raman spektrumu Şekil 2'de verilmiştir [2].

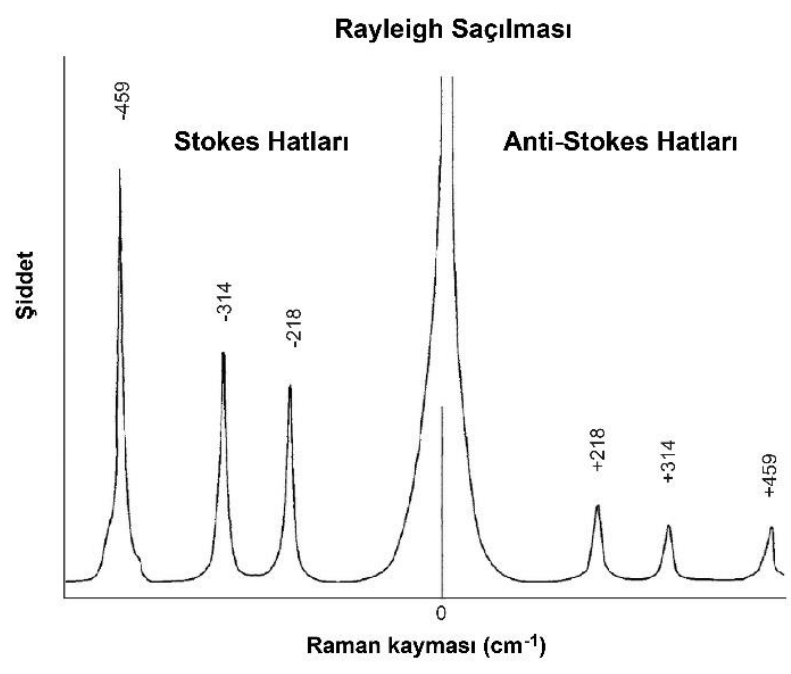

Şekil 2. $\mathrm{CCl}_{4}{ }^{\prime}$ ün Raman spektrumu (488.0 nm uyarımlı).

Bir Raman spektrometresi; 1şık kaynağı (lazer), numune aydınlatma sistemi ve uygun bir spektrometre olmak üzere 3 ana bileşenden oluşmaktadır [1] (Şekil 3). 


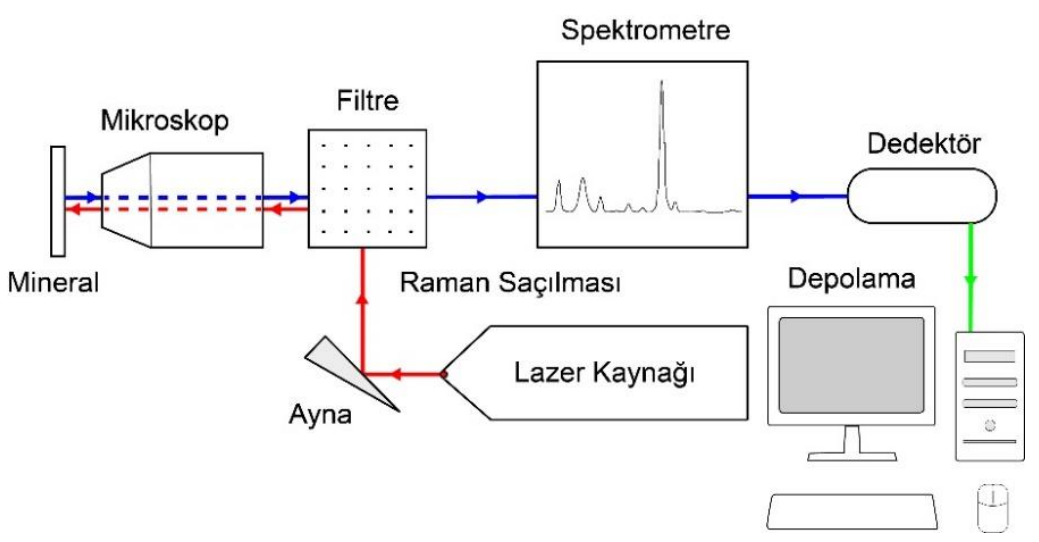

Şekil 3. Raman spektrometresinin ana bileşenleri

Raman spektroskopisinde yaygın olarak kullanılan lazer kaynakları ve dalga boyları Tablo 1'de verilmiştir.

Tablo 1. Raman spektroskopisinde yaygın olarak kullanılan lazer kaynakları ve dalga boyları [1]

\begin{tabular}{cc}
\hline Lazer Kaynağı Tipi & Dalga boyu, $\mathbf{n m}$ \\
\hline Argon iyon & 488.0 veya 514.5 \\
Kripton iyon & 530.9 veya 647.1 \\
Helyum/Neon & 632.8 \\
Diyod lazer & 785 veya 830 (yakın-infrared) \\
Nd/YAG & 1064 (yakın-infrared) \\
\hline
\end{tabular}

İnfrared spektroskopisinde çözücü olarak kullanılamayan su, Raman spektroskopisinde sıklıkla kullanılmaktadır. Suyun Raman spektroskopisi yönteminde kullanılabilen bir çözücü olması, birçok biyokimyasal ve farmasötik maddenin nitel analizinde büyük bir kolaylık sağlamaktadır. Bu nedenle, Raman spektroskopisi biyokimyasal ve tıbbi sistem çalışmaları için oldukça ideal bir yöntemdir [2].

Raman spektroskopisi yönteminde aynı cihazla hem yakın infrared, hem normal infrared, hem de uzak infrared bölgelerindeki bilgiler elde edilebilmektedir. Raman spektroskopisi, infrared spektroskopisine çok benzemekte ve çoğu kez onu tamamlamaktadır [20]. Ayrıca kullanılan malzeme açısından sınırlama olmayışı, ultraviyole (UV), görünür ve yakın IR ışınların kullanılabilmesi, optik olarak ölçüm kolaylığının olması, sulu ortamda rahatlıkla çalışılabilmesi, dipol moment değişimine gerek duyulmaksızın yani simetrik gerilmelerin Raman aktif olması gibi IR'ye göre bir takım avantajları mevcuttur [2].

Raman spektroskopisi yöntemi ile katı, sıvı ve gaz örnekler incelenebilir. Cam malzeme kullanılabilir. Sıvı ve katı numuneler az miktarda bile kolayca analiz edilebilir. Numunenin hazırlanması oldukça kolaydır. Lazer kaynağı numunenin küçük bir alanına kolayca odaklanabilir [1].

Raman spektroskopisi yöntemi ile daha çok nitel analiz yapılmaktadır. Bu amaçla izlenen yol, infrared spektrumlarının yorumunda izlenen yola benzemektedir. Bir molekülün Raman ve infrared spektrumlarının birlikte değerlendirilmesi ile nitel analiz daha kolaylaşmaktadır [19].

Raman spektroskopisinin kullanımı giderek yaygınlaşmakta olup; gıda ve içecek alanlarında, mikrobiyoloji, ilaç geliştirme ve bakteriyoloji gibi yaşamla ilgili bilim dallarında, mikro analizlerde, nükleer güç endüstrisi, kâğıt endüstrisi, polimerler, analitik işlem teknolojileri, proses kontrol, geri dönüşüm endüstrisi, yüzey araştırması, malzeme bilimi, jeoloji, biyoloji, kimya, fizik, sağlık, narkotik, arkeoloji ve uzay araştırmaları gibi çok geniş bir uygulama alanına sahiptir.

Raman spektroskopisinin tıp alanında kullanımı doğrudan insan sağlı̆̆ı ve hayatını ilgilendirdiği için daha da önem kazanmaktadır. İnsanın gırtlak, yemek borusu, mesane, bademcik, mide, prostat vb. gibi organlarının Raman spektrumları incelenebilmekte olup özellikle patolojik incelemelerde kanser bulgularının erken teşhisinde önemli veriler elde edilmiştir [21, 22]. 
Nevşehir Bilim ve Teknoloji Dergisi (2020), 9(2) 99-115

Raman spektroskopisi çalışmaları, günümüzde teknolojik yenilikler ve gelişmeler sayesinde artık in situ (yerinde) yapılabilmektedir. Derin Okyanus Raman In Situ Spektrometresi (DORISS) ile derin denizde jeokimyasal araştırmalar yapılmakta, deniz tabanındaki kayaların, deniz kabuklarının ve gaz hidratların yerinde yüksek kaliteli Raman spektrumları elde edilmektedir [23]. Ayrıca yakın bir gelecekte Mars ve diğer gezegenlerin yüzey mineral karakterizasyonunun da yerinde Raman spektroskopisi kullanılarak belirlenmesi amaçlanmakta olup bu konuda ön çalışmalar yapılmıştır [24, 25, 26].

Raman spektroskopik incelemelerinin örneğe zarar vermeden uygulanabildiği daha önce de belirtilmişti. Ancak filtre kullanımı oldukça önemlidir. Eğer filtre kullanılmazsa bazı örnekler kimyasal bileşimine bağlı olarak reaksiyon göstermekte, yanmakta ve zarar görebilmektedir. Örneğin, kovellin $(\mathrm{CuS})$ mineralinin sirasıyla önce filtresiz (1), sonra kısmen filtreli (2), daha sonra biraz daha fazla filtreli (3) ve en sonunda da tamamen filtreli (4) şekilde Raman ölçümleri yapılarak görüntüleri alınmıştır (Şekil 4). Kovellin minerali kimyasal bileşiminden dolayı filtresiz ya da kısmen filtreli Raman çekimleri sırasında lazerin etki ettiği alanlarda yanmaya uğramış, tam filtreli olarak çekimi yapıldığında ise herhangi bir zarara uğramamıştır. Mineralin tahribata uğraması sırasında oluşan yanmadan dolayı doğru sonuç vermeyebilir.

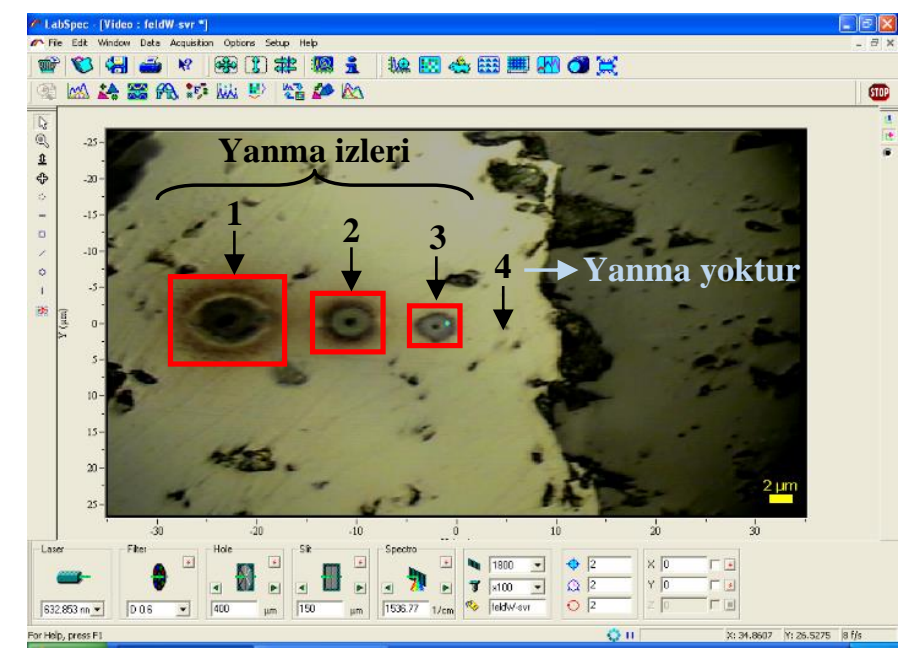

Şekil 4. Bir kovellin (CuS) mineralinin filtresiz (1), kısmen filtreli (2,3) ve filtreli (4) şekilde ölçümleri yapılarak elde edilen Raman görüntüsü

Konfokal Raman Spektrometresi (KRS), konfokal mikroskop ve hassas Raman spektrometresinin kombine edilmesiyle oluşan bir sistemdir. KRS ile minerallerin Raman spektrumları ve aynı zamanda çok hızlı bir şekilde Raman görüntüleri elde edilebilmekte, ayrıca Raman spektrum haritaları oluşturulabilmektedir [27].

Konfokal Raman Spektrometresi (KRS) ile yapılan uygulamalar:

i) Nokta analizi,

ii) Çizgi boyu analiz,

iii) Haritalama ve şiddet analizi şeklinde sıralanabilir.

Nokta analizinde örneğin tek bir noktasının Raman spektrumu elde edilmekte olup ölçüm örneğin çok küçük bir kısmından ve oldukça kısa bir süre (birkaç dakika) içerisinde yapılabilmektedir (Şekil 5). Rutin mineralojik tayinlerde genelde nokta analizi uygulanmaktadır.

Çizgi boyu analizde örnek üzerinde bir hat boyunca belirli aralıklarla peş peşe Raman çekimleri yapılarak Raman spektrumları elde edilmektedir (Şekil 6). Ölçüm yapılan hattın uzunluğuna göre ölçüm süresi değişmektedir. Çizgi boyu analizle örnek üzerindeki zonlanma ve bileşimsel farklılıklar incelenebilmektedir.

Haritalama ve şiddet analizi ölçümlerinde ise örneğin bileşimsel değişimi ve geçiş aralıkları ortaya konulabilmektedir (Şekil 7). Bu ölçümler nokta ve çizgi boyu analizlerine göre fazla nokta seçiminden dolayı çok daha uzun sürede yapılabilmektedir. 
Nevşehir Bilim ve Teknoloji Dergisi (2020), 9(2) 99-115

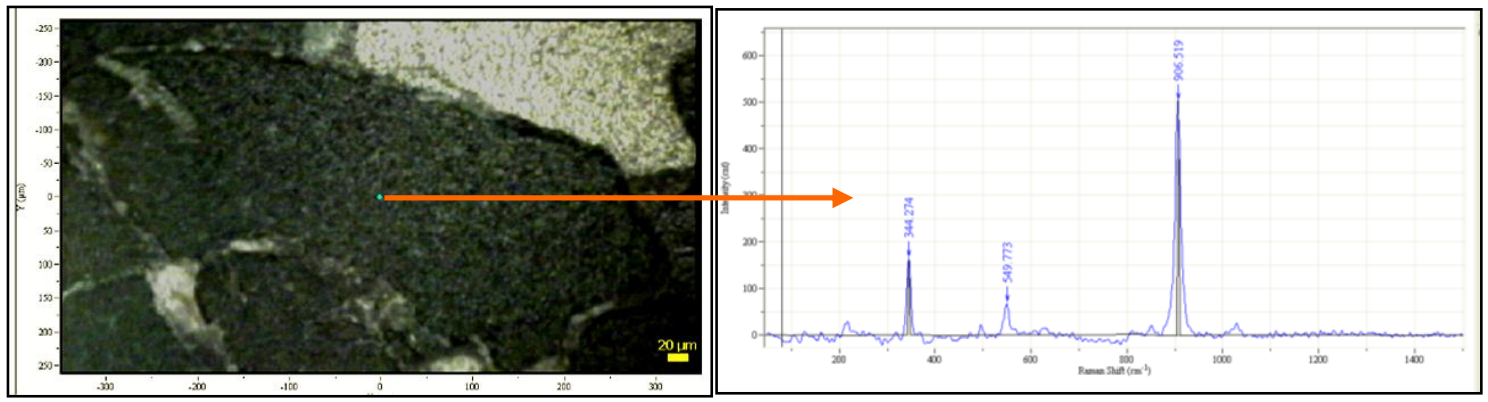

Şekil 5. Nokta analizi yapılmış bir spessartin örneğinin Raman görüntüsü ve spektrumu

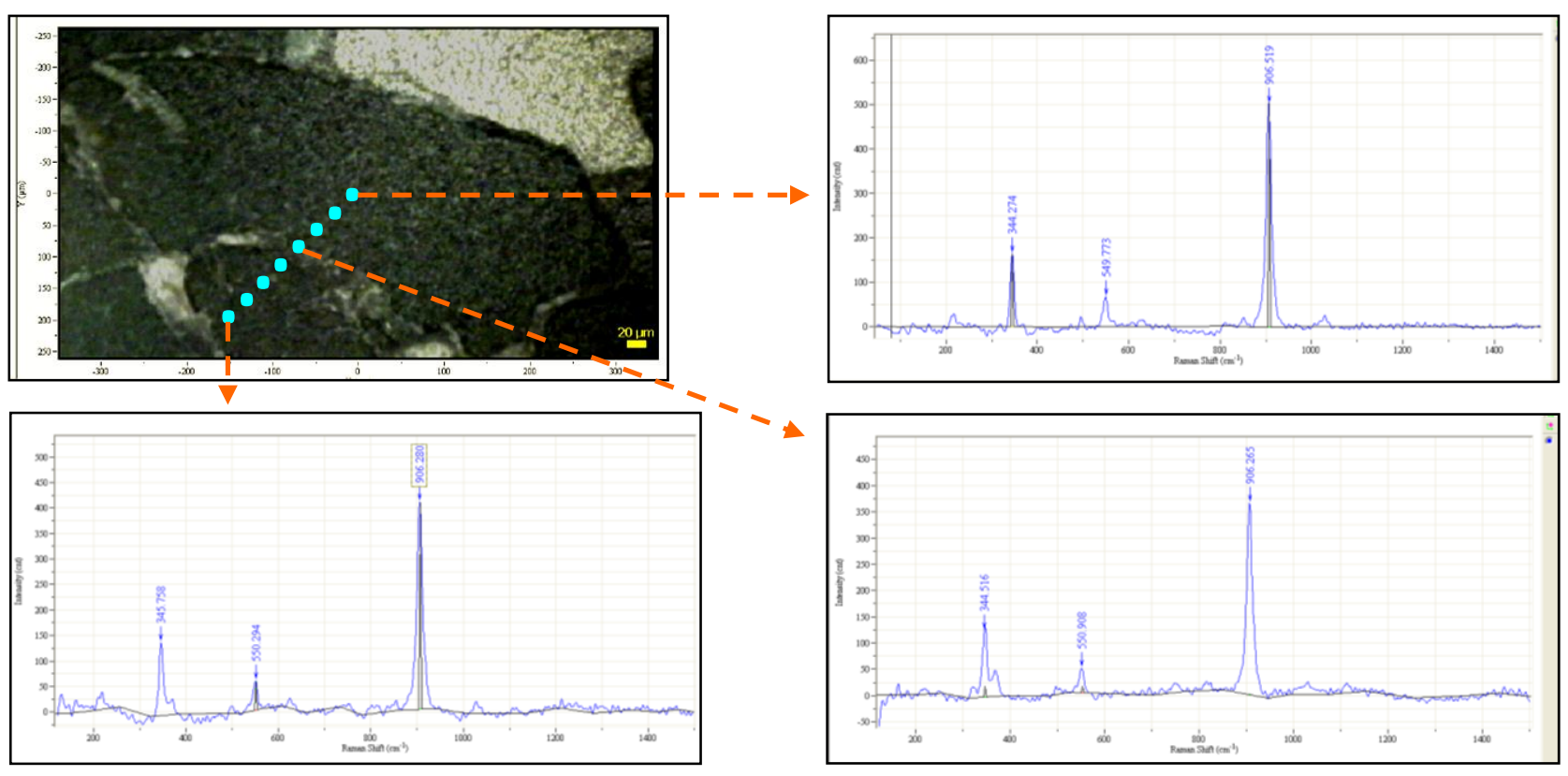

Şekil 6. Çizgi boyu analizi yapılmış bir spessartin örneğinin Raman görüntüsü ve spektrumları

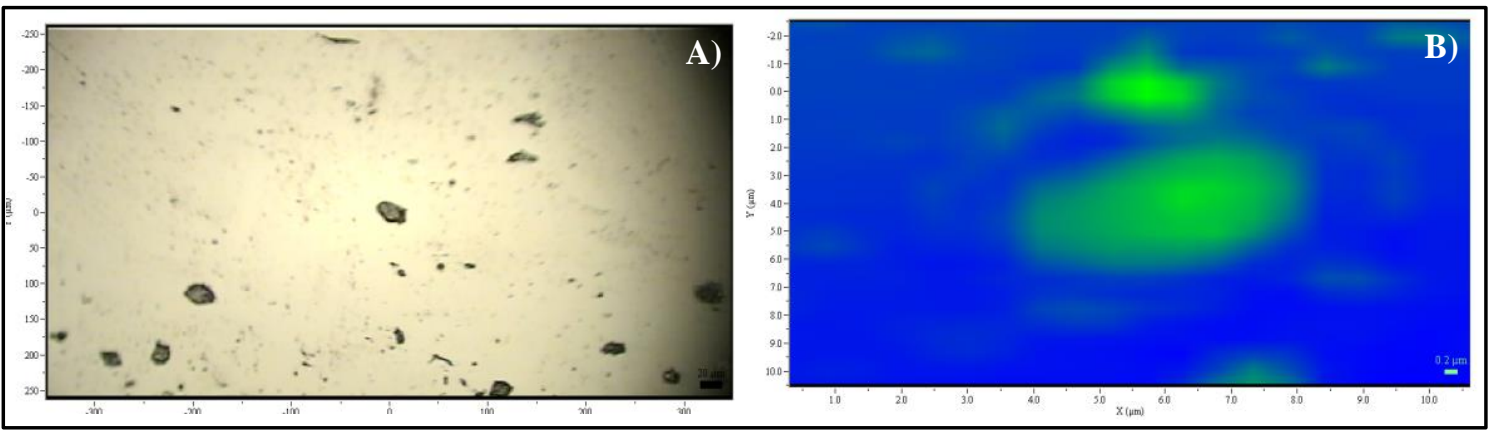

Şekil 7. Raman spektrometresinde haritalama ölçümleri. A) Raman görüntüsü, B) Raman Spektrum haritası

\subsection{Raman Spektroskopisinin Mineraller Üzerindeki Uygulamalart}

Raman'dan adını alan bu titreşimsel spektroskopi türü özellikle daha iyi hassasiyete sahip yeni dedektörlerin geliştirilmesiyle beraber son yıllarda daha çok kullanılmaya başlanmıştır. Raman saçılması, moleküllerin kimyasal yapısı hakkında bilgi vermekte olup bir molekülün titreşimsel spektrumu, o molekül için karakteristik olup parmak izi gibidir [20].

Raman spektroskopisi, birçok farklı disiplinde gerek akademik ve gerekse endüstriyel araştırmalarda yaygın olarak kullanılmaktadır [27, 28]. Raman spektrometre cihazları, teknolojik gelişmelerle birlikte artık çok daha gelişmiş olup sadece laboratuvarlarda değil in situ yani yerinde yapılan çalışmalarda da mobil olarak kullanılabilmektedir [4, 27]. 
Nevşehir Bilim ve Teknoloji Dergisi (2020), 9(2) 99-115

Jeolojik örnekler üzerine yapılan Raman spektroskopi çalışmalarının geçmişi ve sayısı çok fazla değildir. Henüz yeni sayılabilecek bu çalışmalar daha çok magmatik ve metamorfik kayalarda yer alabilen değişik mineral ve mineral gruplarına Raman spektroskopisinin uygulanması ile ilgilidir.

Prieto ve diğ. [29]; FT-Raman ile Galicia (NW İspanya)'daki granitik kayalar (anıtlar) üzerinde yetişen liken florası ile jips neoformasyonunun ilişkisini spektroskopik açıdan ortaya koymuşlardır. Bazı örneklerdeki jipslerin önceki çalışmalarda petrografik mikroskopi, XRD ve elektron mikroskopi ile belirlenemediği halde bu yöntemle belirlendiğini vurgulamışlardır.

Thomas [30]; yeni bir yöntem olarak KRS ile granit ergiyik kapanımlarındaki su içeriğini belirlemiş olup sıvı kapanım ölçümlerinde de kullanılmalarına neden olmuştur.

Thomas [31]; Lazer Raman Mikroprob Spektroskopisi ile granit pegmatitlerdeki sıvı ve ergiyik kapanımlarındaki borik asit konsantrasyonunu belirlemiştir. Santosh ve diğ. [32]; Lazer Raman Mikroskobu ile Güney Hindistan'daki ultra yüksek-sıcaklık granitoyidleri içerisindeki karbonik sıvı kapanımlarını incelemişlerdir. Müller ve diğ. [33]; Raman Spektroskopisi ile Cornwall (İngiltere) ve Erzgebirge'deki (Almanya) granit ergiyik kapanımlarındaki su içeriğini incelemiştir. Mishra ve diğ. [34]; Chottanagpur Gnaysik Kompleksi, Ranchi yöresi (Doğu Hindistan) granitlerindeki süper yoğun karbonik ve hipersalin sıvı kapanımlarını Lazer Raman spektrometre yardımıyla incelemişlerdir.

Yukarıda belirtilen çalışmalar incelendiğinde bunların çoğunlukla granitoyidlerdeki sıvı kapanımlar üzerine yapılmış olduğu görülmektedir. Altta verilen üç çalışma ise yukarıdakilerden farklı olarak doğrudan magmatik ve metamorfik kayalarında ana ve tali mineral olarak yer alabilen silikat minerallerinin Raman spektroskopik özellikleri incelenmiştir. Makreski ve diğ. [35]; Makedonya'dan toplanmış 7 yaygın nezosilikat mineralinin (almandin, spessartin, zirkon, titanit, olivin, disten ve stavrolit) titreşimsel (IR ve Raman) spektrasını incelemişlerdir. Makreski ve diğ. [36]; Makedonya'dan toplanmış tektosilikatlardan alkali feldispat türleri (mikroklin, sanidin) ve albitin titreşimsel spektropi (IR ve Raman spektroskopisi) ve XRD ile spektra-yapı karakterizasyonunu belirlemişlerdir. Jovanovski ve diğ. [37]; Makedonya'dan toplanmış silikat minerallerinin belirlenmesi ve tanımlanması amacıyla titreşimsel (FT-IR ve Raman) spektroskopi ve X-ı̧ıııı toz difraktometrenin birbirini tamamlar nitelikte birlikte kullanımını ele almışlar ve sonuçlarını karşılaştırmışlardır.

Ayrıca tek bir mineral grubunun Raman spektroskopisi üzerine yapılmış birçok çalışma vardır. Granitoyidlerde ana ve tali mineral olarak yer alabilen mineral grupları ve bunların Raman spektroskopileri üzerine yapılan çalışmalardan en önemlileri şunlardır: Granatların Raman spektroskopisini Hofmeister ve Chopelas [38], Mingsheng ve diğ. [39], Kolesov ve Geiger [40], Moroz ve diğ. [41], Bersani ve diğ. [42]; mikaların Raman spektroskopisini Tlili ve diğ. [43], McKeown ve diğ. [44 ve 45], Wang ve diğ. [46]; turmalinlerin Raman spektroskopisini Gasharova ve diğg. [47], McKeown [48], Hoang ve diğ. [49] incelemişlerdir.

Raman spektroskopisinin ülkemizde jeolojide kullanımı sınırlı sayıda araştırmacılar tarafından yapılmıştır (Zoroğlu ve Kadıŏlu [5], Akçe ve Kadıŏlu [6 ve 7], Güllü ve Kadığlu [8], Akçe [9], Deniz [10], Kadıŏglu ve diğ. [11], Üstündağ ve diğ. [12], Deniz ve diğ. [13], Koralay ve diğ. [14], Güllü ve Kadıŏlu [15], Güllü ve diğ. [16], Kadığlu ve diğ. [17], Koralay ve Ören [18]). Bu çalışmalar kapsamında ülkemiz granitoyidlerinde yer alan minerallerin Raman spektrumları kullanılarak granitoyid magmasının kristalleşme süreçlerindeki değişimler üzerine karakteristik incelemelerde bulunulmuştur:

Zoroğlu ve Kadığlu [5], Beypazarı Oymaağaç Granitoyidindeki magma zonlanmasının KRS kullanılarak belirlenmesinde amfibollerin davranışlarını incelemişlerdir. Araştırıcılar; amfibollerin Raman spektrumlarının bölgedeki normal zonlanma ile uyumlu pikler verdiğini tespit etmişlerdir. 
Nevşehir Bilim ve Teknoloji Dergisi (2020), 9(2) 99-115

Koralay ve diğ. [14], Batı Anadolu'da Buldan (Denizli) pegmatitinden alınan; Güllü ve Kadığlu [15] ise Orta Anadolu'da Behrekdağ, Yozgat ve Karakaya granitik kütlelerindeki pegmatitlerden alınan farklı turmalin örneklerinin optik mikroskobi, XRD, XRF ve Konfokal Raman spektroskopik özelliklerini karşılaştırmalı olarak incelemişler, bu yöntemlerin birlikte kullanımının turmalin bileşimlerinin belirlenmesinde oldukça başarılı olduğunu ortaya koymuşlardır . Ayrıca Güllü ve diğg., [16] magmanın kristallenme sürecinin spektroskopik karakterinin ortaya konulması kapsamında yaptıkları çalışmada erken ve geç evrede magmadan kristallenen amfibol minerallerin raman spektrumlarını incelemişlerdir. Çalışmacılar geç evrede kristallenen amfibollerin $\mathrm{Si}_{4} \mathrm{O}_{11}$ bükülme modu OH bağ genliklerinin erken evrede kristallenen amfibol minerallerininkinden daha yüksek olduğunu, bu durumun geç evredeki artık magmadaki $\mathrm{H}_{2} \mathrm{O}$ konsantrasyonu ile ilişkili olabileceğini ifade etmişlerdir. Koralay ve Ören [18] ise Konfokal Raman Spektrometresini XRPD, XRF, EPMA ve gemolojik test yöntemleri ile birlikte kullanarak Çamköy (Aydın) yöresindeki granat kristallerinin süs taşı potansiyelini ve spektroskopik özelliklerini belirlemişlerdir.

\section{Bulgular}

Jeolojik örneklerin içerisindeki minerallerin tanımlanmasına yönelik farklı kaya gruplarından örnekler seçilerek Raman ölçüm analizleri yapılmıştır. Bunun için Orta Anadolu Kristalen Karmaşığındaki temel metamorfik kaya ve onlara sokulum yapan magmatik kayalar içerisindeki minerallerden yararlanarak uygulamalar yapılmıştır.

Yozgat İntrüzif Kompleksi (YİK), Orta Anadolu Kristalen Karmaşı̆̆ının (OAKK) kuzey kenarında yer almakta ve yayılım açısından karmaşı içerisindeki en büyük intrüzif kütleyi temsil eden bir kristalen kaya topluluğudur. YİK, çok farklı bileşim ve jeokimyasal karakterdeki granitik, gabroyik, monzonitik ve siyenitik kayalardan oluşmuştur [6 ve 9]. Bu çalışmada granitik kaya örneklerinden yararlanılmıştır.

Feldispat, mika ve granatlar kayaların oluşumu sırasındaki magmatik kristalleşme ve metamorfik süreçlerin tayin edilmesinde mükemmel bir mineral tarihçesi ortaya sunarlar. Ayrıca bu mineraller, Raman spektrometre çalışmalarında kristal sistemlerindeki yüksek simetriden dolayı belirgin ve yüksek spektrum sergilerler. Çalışma kapsamında Yozgat İntrüzif Kompleksinde yer alan granitik kayalar içerisindeki biyotit ve feldispatlar ile Kırşehir-Kaman civarındaki Orta Anadolu metamorfik kayalarındaki granatların Raman spektroskopik incelemesi yapılmıştır. Bu amaçla YíK ve Orta Anadolu'nun metamorfik temelinden, Raman spektrumlarının korelasyonu ve kristalleşmeleri sırasındaki oluşumlarını tartışmak için farklı feldispat, biyotit ve granatı örnekler toplanmıştır. Yozgat İntrüzif Kompleksindeki minerallerin Raman spektra sonuçları kullanılarak magmanın kristalleşme süreçlerindeki değişimleri ortaya konulmaya çalışılmıştır.

\subsection{Granatların Raman Spektroskopik Incelemesi}

Granat grubu mineraller, Raman spektrometre incelemelerinde silikat yapısı ve kristal sistemlerindeki yüksek simetriden dolayı belirgin ve yüksek spektrum sergilerler. Buna ek olarak granatların son uç üye bileşimlerinin spektrasındaki değişiklikler de karmaşık bir kimyasal bileşime sahip piralspit ve ugranditin incelenmesine imkan verir.

OAKK metamorfik temelinden alınmış granat örneklerinin Raman spektroskopik karakteristikleri belirlenmiştir (Raman görüntüleri, spektrumları ve ölçülen pikle Spectral ID programı kütüphanesindeki referans pik değerleri karşılaştırılarak minerallerin türleri tespit edilmiştir). Bu granat örneklerinden tipik olanlarından birinin Raman spektroskopik karakteristikleri aşağıda verilmiştir (Şekil 8).

Metamorfik temele ait Kırşehir (Kaman) civarından alınan granat örneklerinin Raman spektrası almandin bileşimini vermektedir. İncelenen almandin mineralinin en şiddetli (912.94 cm-1 deki) Raman kayması ve $1038.39 \mathrm{~cm}^{-1}$, deki Raman piki Si-O gerilme titreşimlerinden kaynaklanırken en zayıf $\left(\sim 215 \mathrm{~cm}^{-1}\right.$, deki) Raman kayması ise iki değerlikli katyonların translasyon modundan [T $\left(\mathrm{X}^{2+}\right)$ ] kaynaklanmaktadır. $552.87 \mathrm{~cm}^{-1}$ ve $495.96 \mathrm{~cm}^{-1}$, de gözlenen Raman pikleri Si-O bükülme modlarını; ikinci şiddetli Raman piki (342.64 $\mathrm{cm}^{-1}$ 'deki) ve $370.52 \mathrm{~cm}^{-1}$ 'deki omuz piki ise $\mathrm{SiO}_{4}$ tetrahedronunun rotasyonel modunu $\left[\mathrm{R}\left(\mathrm{SiO}_{4}\right)^{4}\right]$ belirtmektedir $[18,38$ ve 40$]$. 
Nevşehir Bilim ve Teknoloji Dergisi (2020), 9(2) 99-115

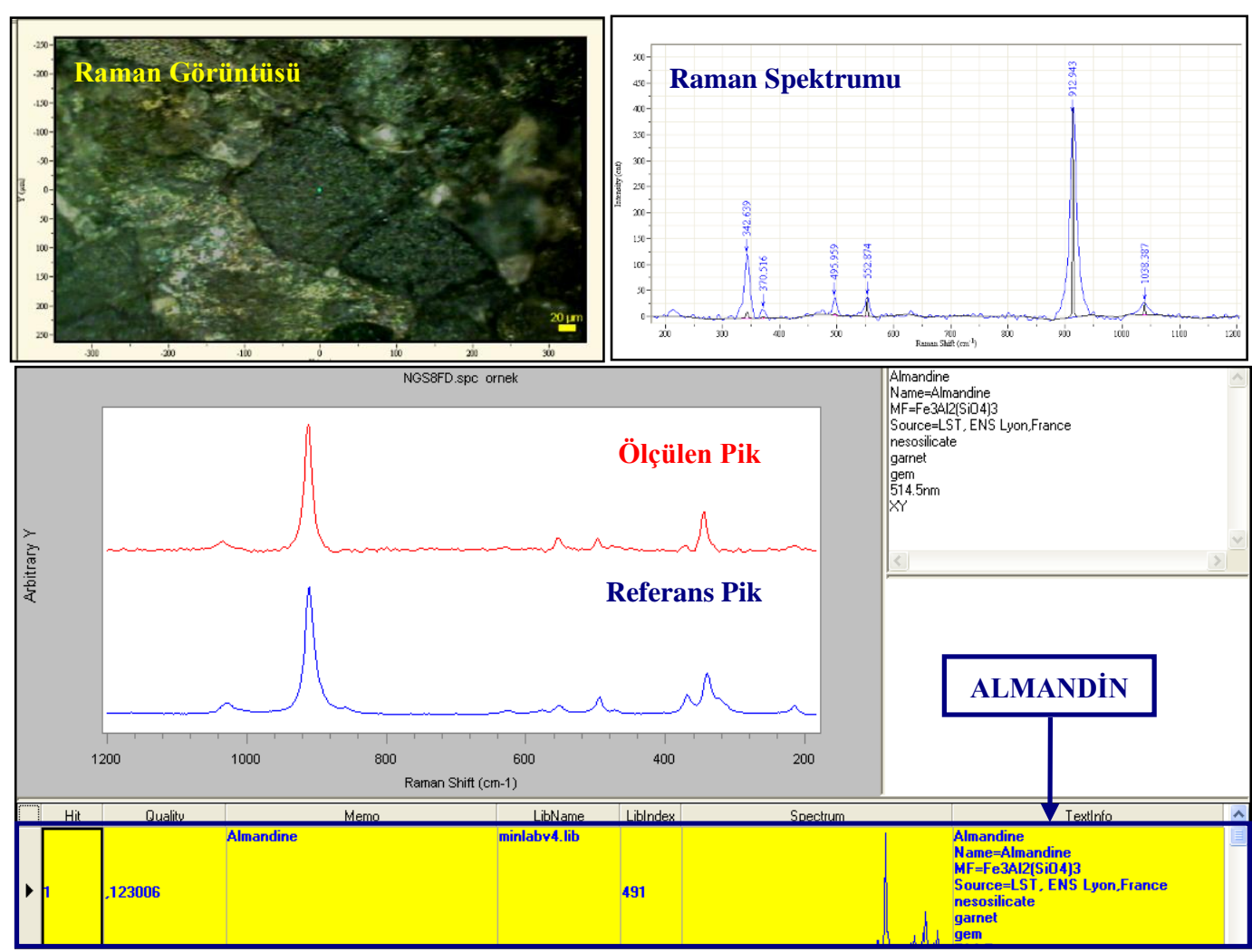

Şekil 8. Kırşehir-Kaman granat mika gnaysındaki granatın Raman spektroskopik karakteristikleri

\subsection{Biyotitlerin Raman Spektroskopik Incelemesi}

Biyotitlerin Raman spektrası çoğu fillosilikatlarda olduğu gibi dört spektral bölgede gözlenmektedir. Bunlar: 1) $3800-3000 \mathrm{~cm}^{-1}$, 2) $1150-800 \mathrm{~cm}^{-1}$, 3) $800-600 \mathrm{~cm}^{-1}$ ve 4) $<600 \mathrm{~cm}^{-1}$ spektral bölgeleridir [46 ve 50] (Şekil 9). 3800$3000 \mathrm{~cm}^{-1}$ spektral bölgesindeki Raman pikleri fillosilikatların yapılarındaki $\mathrm{OH}$ ya da suyun gerilme modundan kaynaklanmaktadır. Filogopit-Biyotit serisinin yapısal-bileşimsel sınıflaması T-O-T $-\mathrm{A}(\mathrm{T}=$ tetrahedral yüzey, $\mathrm{O}=$ oktahedral yüzey, A = ara yüzey büyük katyon veya su) şeklindedir. Filogopit-biyotit serisinin Raman spektraları Fe içeriğindeki artışa göre değişmektedir [46] (Şekil 10).

Çalışma kapsamında Yozgat İntrüzif Kompleksi granitoyidleri içerisindeki biyotitlerin Raman spektraları incelenmiş ve Raman spektroskopik karakteristikleri belirlenmiştir. Analiz edilen mika minerallerinin polarizan mikroskop görüntüleri Şekil 11 ve Şekil 12'de verilmiştir. İncelenen mika minerallerinin Raman spektra sonuçları Fe içeriğindeki değişime bağlı olarak filogopit $(\mathrm{Fe}<0.33)$ ve biyotit $(\mathrm{Fe}>0.33)$ bileşimlerini vermektedir (Şekil 11, Şekil 12). Bu iki farklı bileşimsel spektra incelenen mikaların kökeninin farklı olabileceğini göstermektedir.

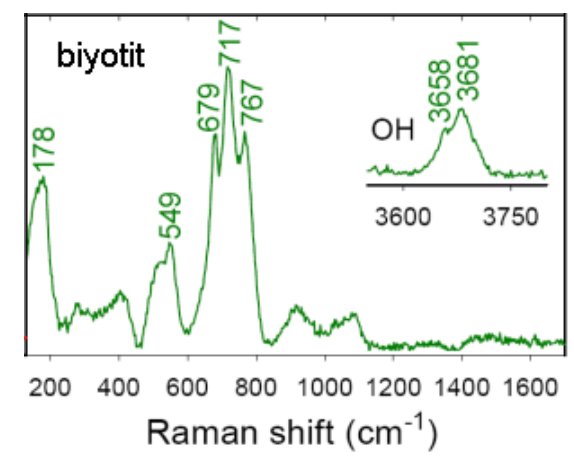

Şekil 9. Biyotitin tipik Raman spektrası [50] 
Nevşehir Bilim ve Teknoloji Dergisi (2020), 9(2) 99-115

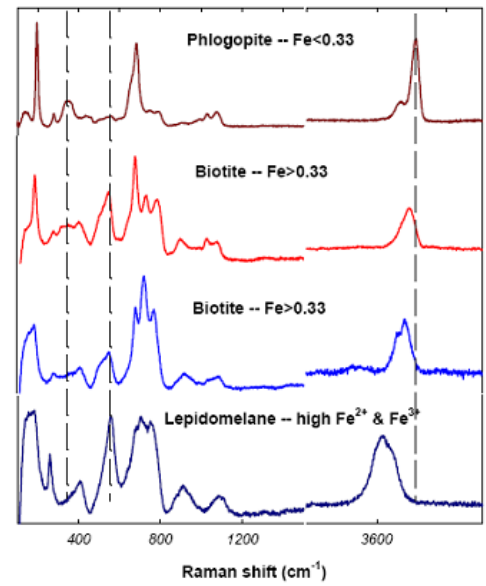

Şekil 10. Filogopit-biyotit serisinin artan Fe içeriğine göre Raman spektraları [46]
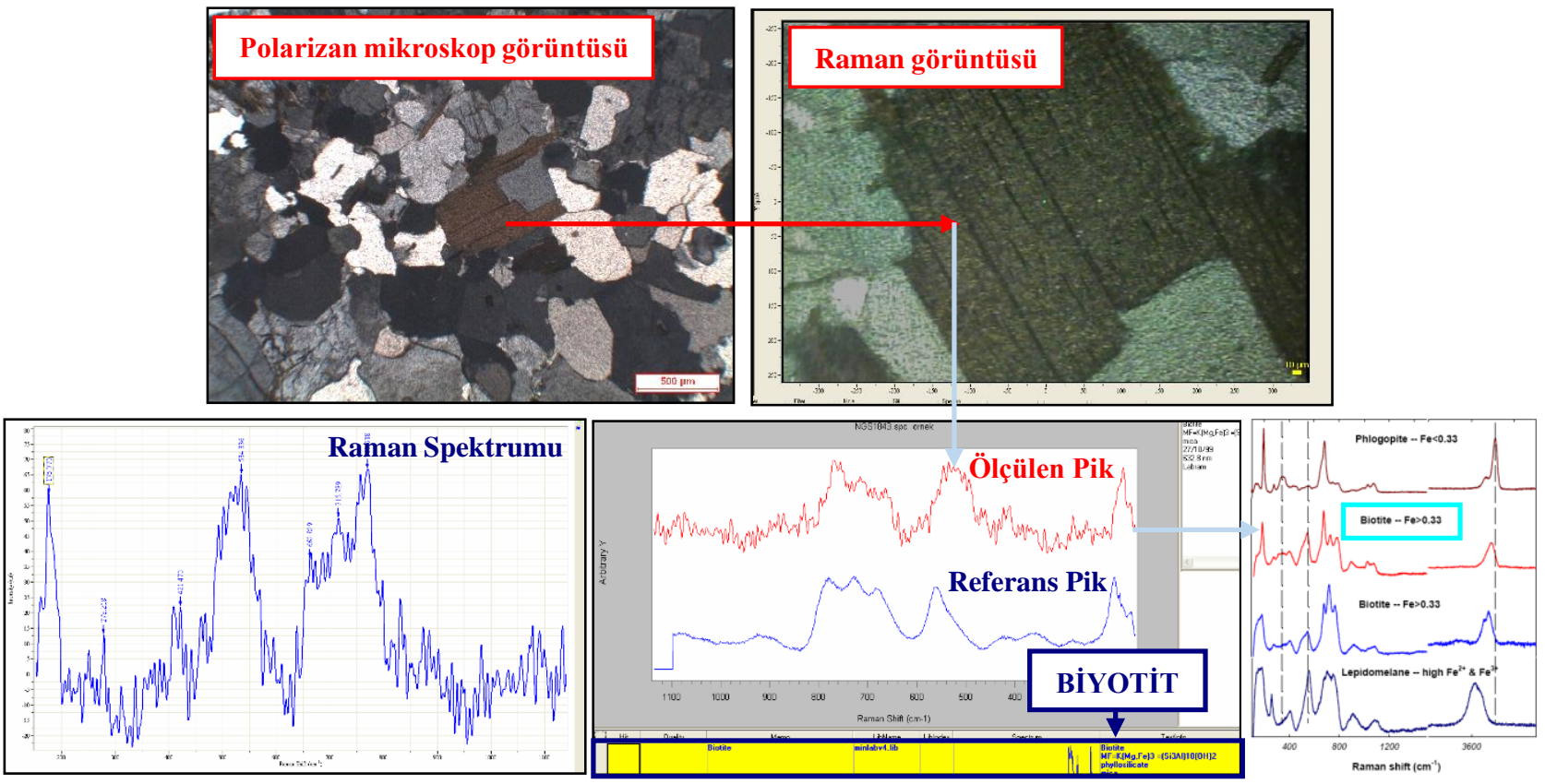

Şekil 11. YİK granitoyidlerinden alınan 1 nolu mika mineralinin Raman spektroskopik karakteristikleri
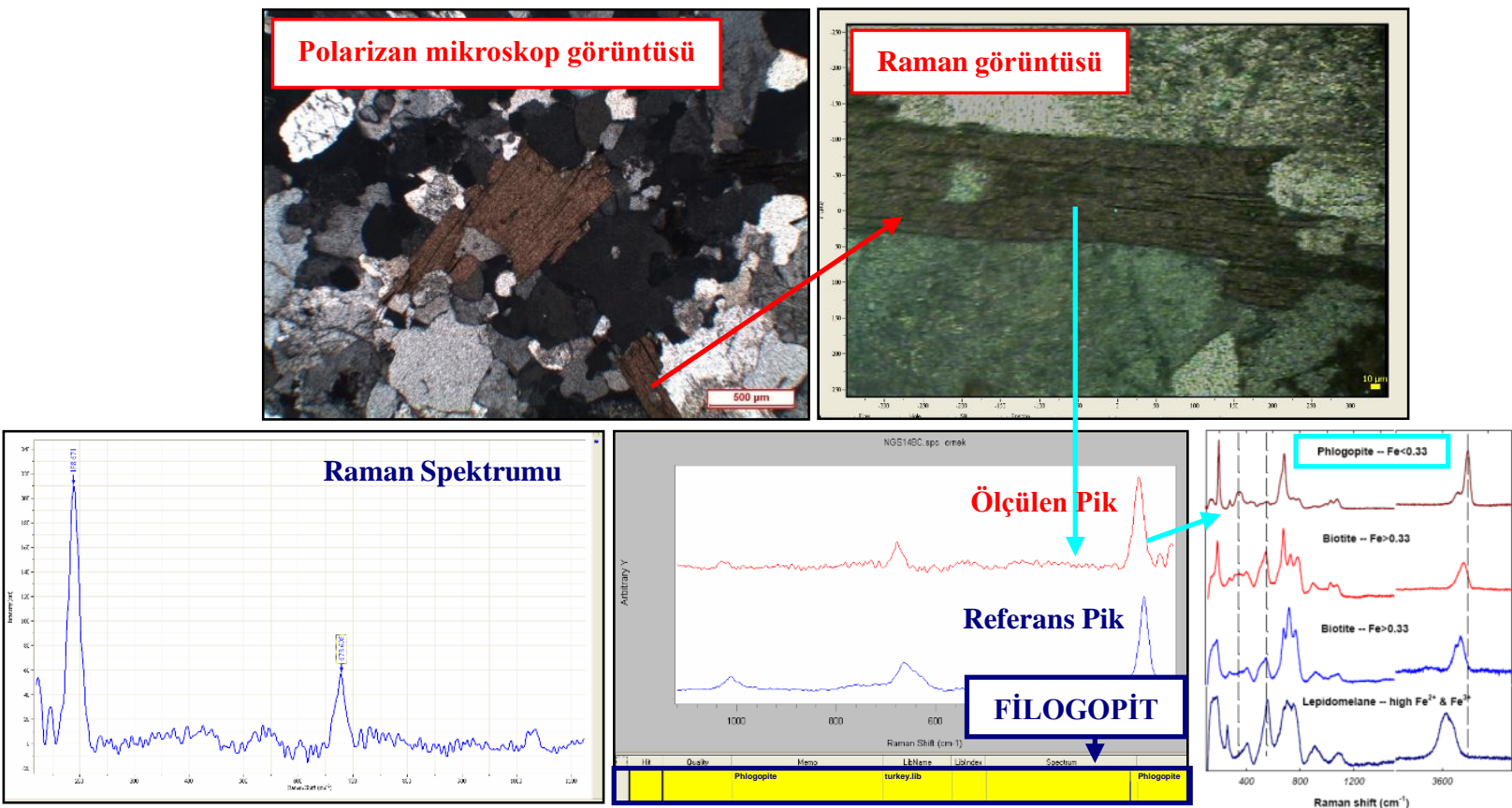

Şekil 12. YİK granitoyidlerinden alınan 2 nolu mika mineralinin Raman spektroskopik karakteristikleri 


\subsection{Feldispatların Raman Spektroskopik İncelemesi}

Feldispatların Raman spektraları üç spektral bölgede gözlenmektedir (Şekil 13). Feldispatların tipik Raman spektraları, güçlü Raman bandlarının karakteristik özellikleri ve yapısal-bileşimsel sınıflaması aşağıdaki tabloda detaylı bir şekilde verilmiştir [25] (Tablo 2).

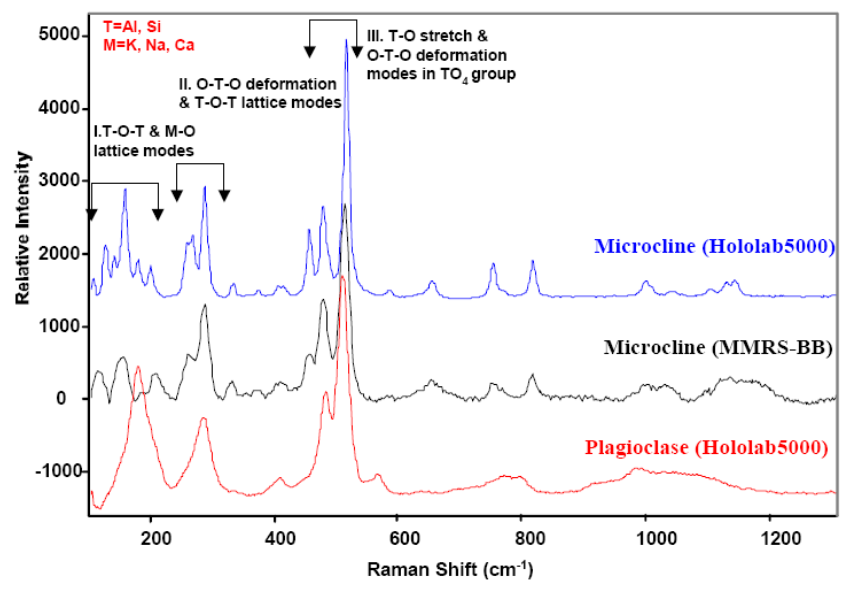

Şekil 13. Bazı feldispatların tipik Raman spektraları [25]

Tablo 2. Feldispatların Raman karakteristikleri [25]

\begin{tabular}{|c|c|c|c|c|c|}
\hline \multirow[b]{2}{*}{ Mineral Name } & \multirow[b]{2}{*}{ Chemical Composition } & \multirow[b]{2}{*}{$\begin{array}{l}\text { Structure \& Ordering of Al- } \\
\text { Si distribution }\end{array}$} & \multicolumn{3}{|c|}{ Characteristic Features of Strong Raman Bands } \\
\hline & & & $\begin{array}{l}\text { Region III } \\
{\left[\mathrm{TO}_{4}\right] \text { modes }}\end{array}$ & $\begin{array}{l}\text { Region II }\left[\mathrm{TO}_{4}\right] \\
\text { \& lattice modes }\end{array}$ & $\begin{array}{l}\text { Region I } \\
\text { lattice modes }\end{array}$ \\
\hline Microcline & $\mathrm{KAISi}_{3} \mathrm{O}_{8}$ (end member) & Triclinic, Highly ordered & $\begin{array}{l}513 \\
476 \\
453\end{array}$ & $\begin{array}{l}285 \\
265\end{array}$ & $\begin{array}{l}157 \\
126\end{array}$ \\
\hline Orthoclase & $\begin{array}{l}\mathrm{KAISi}_{3} \mathrm{O}_{8} \\
\text { (near end member) }\end{array}$ & $\begin{array}{l}\text { Monoclinic, The Al and one } \\
\text { Si disordered. }\end{array}$ & $\begin{array}{l}513-514 \\
475 \pm 2\end{array}$ & $282 \pm 1$ & $154 \pm 2$ \\
\hline Sanidine & $\begin{array}{l}\mathrm{KAISi}_{3} \mathrm{O}_{8} \\
\text { (near end member) }\end{array}$ & $\begin{array}{l}\text { Monoclinic, The Al and all } \\
\text { three Si disordered. }\end{array}$ & $\begin{array}{l}514 \\
475 \pm 1\end{array}$ & $284 \pm 2$ & $\begin{array}{l}114 \\
164 \pm 2\end{array}$ \\
\hline $\begin{array}{l}\text { Anorthoclase (K_Al- } \\
\text { bite) }\end{array}$ & $\mathrm{Na}_{\sim 0.8} \mathrm{~K}_{\sim 0.4} \mathrm{AlSi}_{3} \mathrm{O}_{8}$ & Triclinic, Highly ordered & $\begin{array}{l}512.5 \pm 0.5 \\
474 \pm 1\end{array}$ & 284 & 166 \\
\hline Low-T albite & $\begin{array}{l}\mathrm{NaAlSi}_{3} \mathrm{O}_{8} \\
\text { (end members) }\end{array}$ & Triclinic, Highly ordered & $\begin{array}{l}507 \\
479 \\
456\end{array}$ & $290 \pm 0.5$ & $\begin{array}{l}208 \pm 1 \\
184 \pm 2 \\
151\end{array}$ \\
\hline High-T Plagioclases & $\begin{array}{l}\mathrm{Na}_{x} \mathrm{Ca}_{1-x} \mathrm{Al}_{1+\times} \mathrm{Si}_{3-x} \text { (inter- } \\
\text { mediate } \mathrm{Na} \text {, Ca mix- } \\
\text { tures) }\end{array}$ & $\begin{array}{l}\text { Triclinic, Structurally and } \\
\text { compositionally disordered }\end{array}$ & $\begin{array}{l}509 \pm 1 \\
482 \pm 2\end{array}$ & $284 \pm 3$ & $179 \pm 4$ \\
\hline $\begin{array}{l}\text { Anorthite \& high } \mathrm{Ca}^{++} \text {, } \\
\text { low-T plagioclases }\end{array}$ & $\begin{array}{l}\mathrm{CaAl}_{2} \mathrm{Si}_{2} \mathrm{O}_{8} \\
\text { (end members) }\end{array}$ & Triclinic, Highly ordered & $\begin{array}{l}503 \pm 1 \\
484\end{array}$ & $\begin{array}{l}285 \\
250 \pm 2\end{array}$ & $\begin{array}{l}183 \pm 2 \\
140-150\end{array}$ \\
\hline
\end{tabular}

Çalışma kapsamında Yozgat İntrüzif Kompleksi granitoyidleri içerisindeki feldispatların Raman spektraları incelenmiş ve Raman spektroskopik karakteristikleri belirlenmiştir. Ölçülen Raman pikleri tipik feldispat pikleri ile karşılaştırılarak güçlü Raman bandlarının karakteristik özellikleri ve yapısal-bileşimsel özellikleri belirlenmiştir. Feldispat minerallerinin Raman spektroskopik ölçümleri sonucunda albit bileşiminde plajiyoklaz; ortoklaz ve anortoklaz bileşiminde de K-feldispat mineralleri tespit edilmiştir. Bu minerallerin ayırtman Raman spektrumları Şekil 14, Şekil 15 ve Şekil 16'da verilmiştir.

\section{Tartışma ve Sonuç}

Bu çalışmada Raman saçılması ve spektroskopisinin tanımı, analitik uygulamaları, titreşim yorumu, mineralojide ve özellikle magmatik ve metamorfik kayalarda kullanımı anlatılmıştır.

Raman spektroskopisi birçok uygulama alanına sahip olup son yıllarda jeoloji ve özellikle mineralojik incelemelerde giderek artan bir sıklıkta kullanılmaya başlanmıştır. Raman Spektroskopisi; mineralojik ve petrolojik çalışmalarda optik mikroskopik, kimyasal ve diğer spektroskopik incelemelerin çok önemli bir tamamlayıcısı ve destekleyicisi konumunda, hatta bazı durumlarda rutin polarizan mikroskop incelemesi, XRD ve elektron mikroprob gibi ileri analitik yöntemlerle dahi belirlenemeyen mineral ve mineral gruplarının türlerine kadar hassas bir şekilde tayin edilebilmesini sağlamaktadır. 


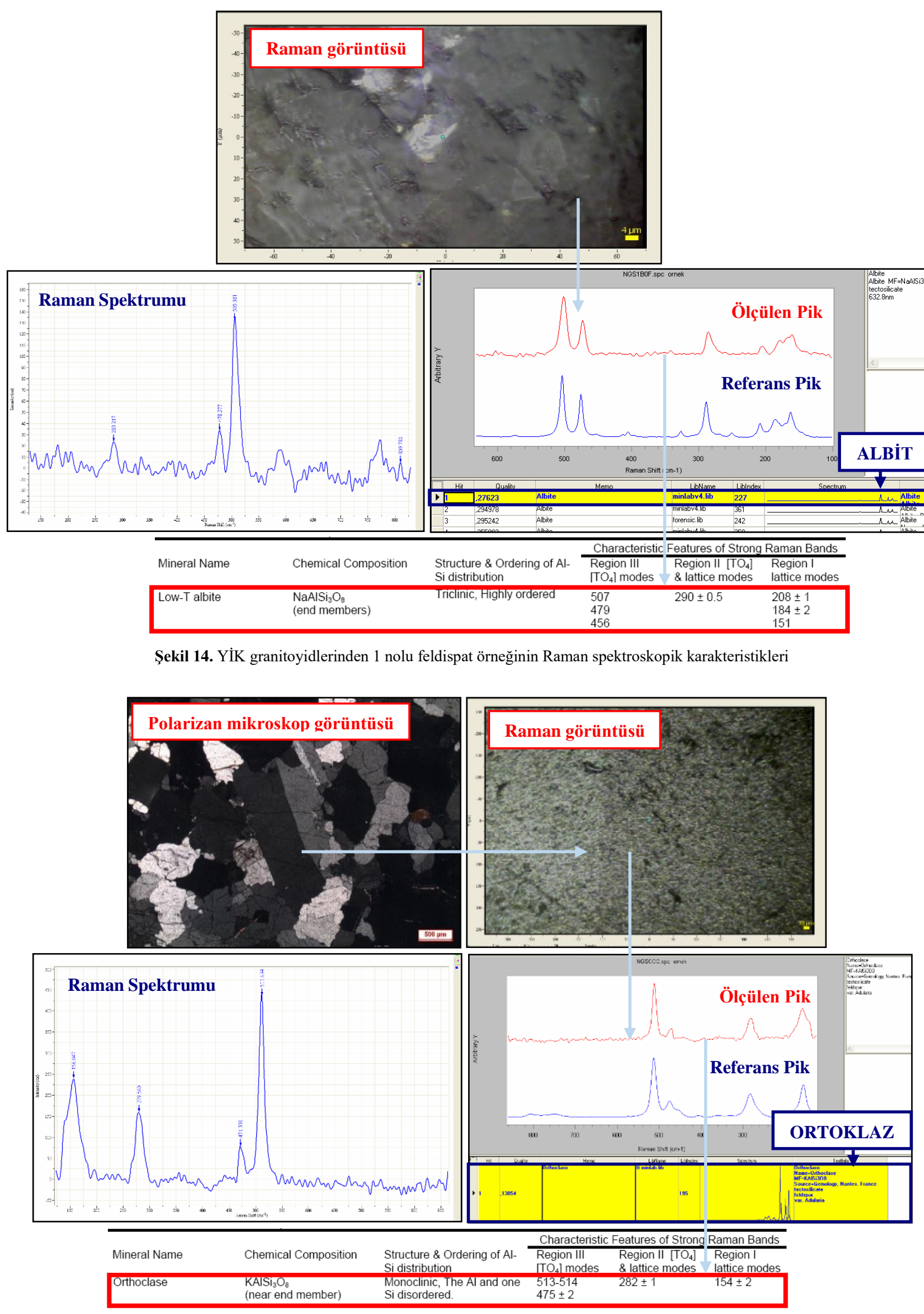

Şekil 15. YİK granitoyidlerinden 2 nolu feldispat örneğinin Raman spektroskopik karakteristikleri 


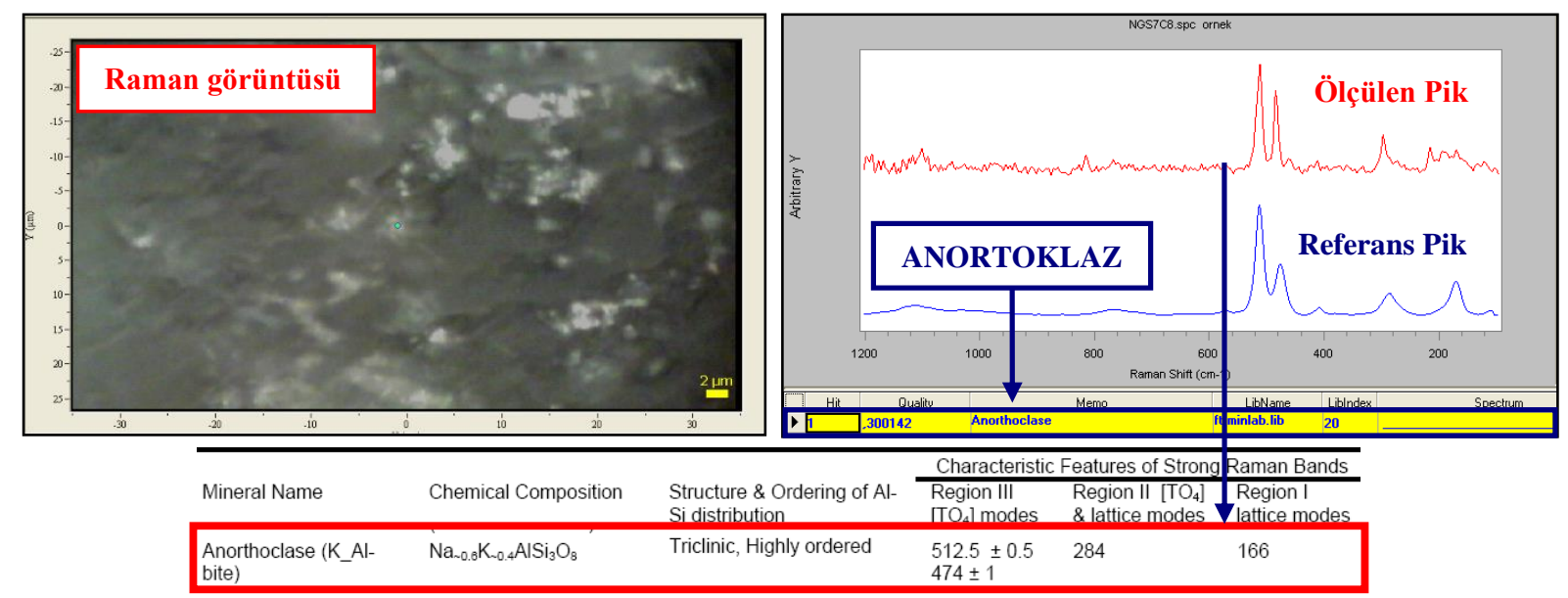

Şekil 16. YİK granitoyidlerinden 3 nolu feldispat örneğinin Raman spektroskopik karakteristikleri

Özellikle yakın bileşime sahip olan mineraller bu yöntemle kolayca ayırt edilerek tanımlanabilmektedir. Raman spektroskopisi tahribatsız bir teknik olarak, değerli taşlar ve mücevherleri analiz etmek için de ideal bir araçtır. XRD ölçümlerinde kaya örneği öncelikle ögütülerek toz haline getirilmekte (tahrip edilmekte) olup sonrasında yapılan ölçüm neticesinde tüm örneğin içindeki oran $1 \% 5$ 'in altında bulunan mineraller teşhis edilmeyebilir. Oysa Raman spektroskopik çalışmalarında minerale herhangi bir zarar vermeksizin, doğrudan seçilen bir noktanın analiz sonucuna ulaşmak mümkündür. Bunun yanında Raman incelemelerinde numune hazırlama işleminin oldukça kolay olması, küçük numunelerde bile ölçüm yapılabilmesi, ölçüm zamanının kısalığı, kullanımının kolaylığı ve nispeten düşük maliyetli bir sistem olması gibi avantajları bu yöntemin mineral adlandırma ve tanımlamalarında giderek daha ön plana çıkmasına ve yaygınlaşmasına neden olmaktadır.

Çalışma kapsamında; Yozgat İntrüzif Kompleksi (YİK) granitoyidlerinde yer alan feldispat (plajiyoklaz, ortoklaz ve anortoklaz) ve biyotitlerin tipik Raman spektroskopik özellikleri ortaya konularak ayrıntılı adlandırmaları yapılmıştır. Ayrıca Orta Anadolu Kristalen Karmaşı̆̆ı (OAKK) içerisinde Kırşehir (Kaman) civarındaki metamorfik kayalarda yer alan granatların Raman spektroskopisi incelenmiştir.

Feldispat, biyotit ve granatlar, kayaların oluşumu sırasındaki magmatik kristalleşme ve metamorfik süreçlerin tayin edilmesi açısından önemli bilgiler ortaya sunarlar [51, 52 ve 53]. Kristal sistemlerindeki yüksek simetriden dolayı da Raman spektroskopi çalışmalarında belirgin ve yüksek spektrum sergilerler.

Orta Anadolu metamorfik temelinden alınan (Kırşehir-Kaman civarındaki) granatların Raman spektrası almandin bileşimini vermektedir. Trioktahedral fillosilikatlardan filogopit-biyotit serisi mineraller demir içeriğine göre farklı Raman spektraları sergilemektedirler. YİK granitoyidlerindeki biyotitlerin Raman spektra sonuçları Fe içeriğindeki değişime bağlı olarak filogopit $(\mathrm{Fe}<0.33)$ ve biyotit $(\mathrm{Fe}>0.33)$ bileşimlerini vermektedir. Bu iki farklı bileşimsel spektra bu mikaların kökeninin farklı olabileceğini göstermektedir. YİK granitoyidleri içerisindeki feldispatların Raman spektraları incelenmiş ve Raman spektroskopik karakteristikleri belirlenmiştir. Raman spektrumlarına göre albit, ortoklaz ve anortoklaz türü feldispatlar belirlenmiş ve güçlü Raman bandlarının yapısal-bileşimsel özellikleri ortaya konmuştur.

Tüm bu çalışmalar sonucunda Raman spektroskopisinin minerallerin tahribatsız olarak adlandırma ve tanımlanmaları için kullanılan hızlı, kolay ve güvenilir bir yöntem olduğunu göstermiştir.

\section{Kaynaklar}

[1] Skoog D. A., Holler F. J., Nieman T. A., "Principles of Instrumental Analysis" 5th Ed., Saunders College Publishing, Philadelphia, 849s, 1998 (Çeviri: Kılıç E., Köseoğlu F., Yılmaz H., Bilim Yayıncılık, Ankara)

[2] Ferraro J. R., Nakamoto K., Brown C. W., "Introductory Raman Spectroscopy” 2nd Ed., Academic Press, San Diego, 434s, 2003 
[3] McMillan P. F., Hofmeister, A. M., "Infrared and Raman spectroscopy" In: Spectroscopic Methods in Mineralogy and Geology (F. C. Hawthorne, editor), Chapter 4, Reviews in Mineralogy, 18 (1), Mineralogical Society of America, Washington D.C., 99-159, 1988

[4] Nasdala L., Smith D. C., Kaindl R., Gaft M., Ziemann M. A., "Raman spectroscopy: Analytical perspectives in mineralogical research" In: Spectroscopic Methods in Mineralogy (A. Beran and E. Libowitzky, editors), Chapter 7, EMU Notes in Mineralogy, Vol. 6, Eötvös University Press, Budapest, 281-344, 2004

[5] Zoroğlu O., Kadığlu Y. K., "Behavior of amphiboles in the determination of magma zoning using confocal Raman spectrometry: Beypazarı Oymaağaç granitoid-Ankara Turkey" The Second International Conference on Geo-Resources in The Middle East and North Africa (GRMENA-2), February 24-28, Proceedings, 110-111 s, Cairo, Egypt, 2007

[6] Akçe M. A., Kadığlu Y. K., "Yozgat İntrüzif Kompleksindeki Granatların Raman Konfokal Spektroskopik Karakteristikleri” 62. Türkiye Jeoloji Kurultayı 13-17 Nisan, Bildiri Özleri Kitabı, 614-615 s, Ankara, 2009

[7] Akçe M. A., Kadıŏlu Y. K., "Raman Spektroskopisinin Mineralojide Kullanımı: Yozgat İntrüzif Kompleksi, Orta Anadolu” XI. Ulusal Spektroskopi Kongresi 23-26 Haziran, Bildiri Özetleri Kitabı, 14 s, Ankara, 2009

[8] Güllü B., Kadığlu Y. K., “Orta Anadolu'daki Farklı Turmalinlerin Konfokal Raman Spektrometrisi ile Tanımlanması" 62. Türkiye Jeoloji Kurultayı 13-17 Nisan, Bildiri Özleri Kitabı, 630-631 s, Ankara, 2009

[9] Akçe M. A., "Yozgat İntrüzif Kompleksinin Jeolojisi, Petrolojisi ve Orta Anadolu Kristalen Karmaşığındaki Zamansal ve Mekansal Konumu" Ankara Üniversitesi, Fen Bilimleri Enstitüsü, Doktora Tezi, 240s, Ankara, 2010

[10] Deniz K., "Buzlukdağı (Kırşehir) Alkali Magmatik Kayaçların Jeolojisi, Petrolojisi ve Konfokal Raman Spektrometresi ile İncelenmesi” Ankara Üniversitesi, Fen Bilimleri Enstitüsü, Yüksek Lisans Tezi, 138s, Ankara, 2010

[11] Kadıŏlu Y. K., Koralay T., Zoroğlu O., Güllü B., Akçe M. A., Deniz K., Yıldırım B., "Differentiation of Ophiolitic and Nonophiolitic Gabbros using Confocal Raman Spectroscopy: Central Anatolia Turkey" Mineralogical Magazine, 75 (3), 1133 s, 2011

[12] Üstündağ İ., Akçe M. A., Deniz K., Kadıŏlu Y. K., Üstündağ Z., "Raman Spektrometresiyle Jeolojik Örneklerin Karakterizasyonu" Uluslararası Katılımlı XII. Ulusal Spektroskopi Kongresi 18-22 Mayıs, Bildiri Özleri Kitabı, 167 s, Antalya, 2011

[13] Deniz K., Kadığlu Y. K., Koralay T., Güllü B., Akçe M. A., Kılıç C. O., "Petrology and Raman Characterization of Leucitites within the Ultrapotassic Rocks: Afyon, NW Turkey" Mineralogical Magazine, 77 (5), 974 s, 2013

[14] Koralay T., Kadıŏlu Y. K., Jiang S. Y., "Determination of Tourmaline Composition in Pegmatite From Buldan, Denizli (Western Anatolia, Turkey) Using XRD, XRF, and Confocal Raman Spectroscopy" Spectroscopy Letters, 46, 499-506, 2013

[15] Güllü B., Kadığlu Y. K., "Use of tourmaline as a potential petrogenetic indicator in the determination of host magma: CRS, XRD and PED-XRF methods" Spectrochimica Acta Part A: Molecular and Biomolecular Spectroscopy, 183, 68-74, 2017

[16] Güllü B., Kadıŏglu Y. K., Koralay T., Deniz K., "Raman Characteristics of Gücünkaya (Aksaray) Gabbroic Rocks, Central Anatolia-Turkey" $19^{\text {th }}$ International Multidisciplinary Scientific GeoConference SGEM 2019, 30 June - 6 July, Proceedings, Vol. 19, 475-482, Bulgaria, 2019

[17] Kadığlu Y. K., Deniz K., Koralay T., Güllü B. "Nature of The Gabbro in Central Anatolia: Geological Observation and Spectroscopic Applications, Turkey" $19^{\text {th }}$ International Multidisciplinary Scientific GeoConference SGEM 2019, 30 June - 6 July, Proceedings, Vol. 19, 377-384, Bulgaria, 2019 
Nevşehir Bilim ve Teknoloji Dergisi (2020), 9(2) 99-115

[18] Koralay T., Ören U., "Determination of spectroscopic features and gemstone potential of garnet crystals from the Çamköy region (Aydın - SW Turkey) using XRPD, XRF, Confocal Raman Spectroscopy, EPMA and gemological test methods" Periodico di Mineralogia, 89 (2), 105-123, 2020

[19] URL-1, (2020) Karacan M. S., "Enstrümental Analiz" Ders Notları, Gazi Üniv. Fen Fak. Kimya Böl., [PDF belgesi]. http://w3.gazi.edu.tr/ mkaracan/enstrumental.pdf (20.07.2020)

[20] Gündüz T., “İnstrümental Analiz” 5. Baskı, Gazi Büro Kitabevi, Ankara, 607s, 1999

[21] Stone N., Kendall C., Shepherd N., Crow P., Barr H., "Near-infrared Raman spectroscopy for the classification of epithelial pre-cancers and cancers" Journal of Raman Spectroscopy, 33 (7), 564-573, 2002

[22] Çulha M., “Tıbbi Sorunlara Nanoteknoloji Destekli Spektroskopik Çözümler” XI. Ulusal Spektroskopi Kongresi 23-26 Haziran, Bildiri Özetleri Kitabı, 15 s, Ankara, 2009

[23] White S. N., Kirkwood W. J., Sherman A. D., Brown M. O., Henthorn R., Salamy K. A., Walz P. M., Peltzer E. T., Brewer P. G., "Development and deployment of a precision underwater positioning system for in situ laser Raman spectroscopy in the deep ocean” Deep Sea Research Part I: Oceanographic Research Papers, 52 (12), 2376-2389, 2005

[24] Haskin L. A., Wang A., Rockow K. M., Jolliff B. L., Korotev R. L., Viskupic K. M. "Raman spectroscopy for mineral identification and quantification for in situ planetary surface analysis: a point count method" Journal of Geophysical Research: Planets, 102 (E8), 19293-19306, 1997

[25] Freeman J. J., Wang A., Kuebler K. E., Haskin L. A., "Raman spectroscopic characterization of the feldspars implications for in situ surface mineral characterization in planetary exploration" The $34^{\text {th }}$ Lunar and Planetary Science Conference, March 17-21, Proceedings, \#1676, League City, Texas, 2003

[26] Rull Pérez F., Martinez-Frias J., "Raman spectroscopy goes to Mars” Spectroscopy Europa, 18 (1), 18-21, 2006

[27] Smith E., Dent G., "Modern Raman Spectroscopy - A Practical Approach" John Wiley \& Sons Ltd, Chichester, 210s, 2005

[28] Das R. S., Agrawal Y. K., "Raman spectroscopy: Recent advancements, techniques and applications" Vibrational Spectroscopy, 57 (2), 163-176, 2011

[29] Prieto B., Seaward M. R. D., Edwards H. G. M., Rivas T., Silva B. “An Fourier transform-Raman spectroscopic study of gypsum neoformation by lichens growing on granitic rocks" Spectrochimica Acta Part A: Molecular and Biomolecular Spectroscopy, 55 (1), 211-217, 1999

[30] Thomas R., "Determination of water contents in granite melt inclusions by confocal laser Raman microprobe spectroscopy" American Mineralogist, 85 (5), 868-872, 2000

[31] Thomas R., "Determination of the $\mathrm{H}_{3} \mathrm{BO}_{3}$ concentration in fluid and melt inclusions in granite pegmatites by laser Raman microprobe spectroscopy" American Mineralogist, 87 (1), 56-68, 2002

[32] Santosh M., Tanaka K., Yoshimura Y., "Carbonic fluid inclusions in ultrahigh-temperature granitoids from southern India" Comptes Rendus Geoscience, 337 (3), 327-335, 2005

[33] Müller A., Thomas R., Wiedenbeck M., Seltmann R., Breiter, K., "Water content of granitic melts from Cornwall and Erzgebirge: A Raman spectroscopy study of melt inclusions" European Journal of Mineralogy, 18 (4), 429-440, 2006

[34] Mishra B., Saravanan C. S., Bhattacharya A., Goon A., Mahato S., Bernhardt H. J., "Implications of super dense carbonic and hypersaline fluid inclusions in granites from the Ranchi area, Chottanagpur Gneissic Complex, Eastern India" Gondwana Research, 11 (4), 504-515, 2007

[35] Makreski P., Jovanovski G., Stojančeska S., "Minerals from Macedonia XIII: Vibrational spectra of some commonly appearing nesosilicate minerals" Journal of Molecular Structure, 744-747, 79-92, 2005 
Nevşehir Bilim ve Teknoloji Dergisi (2020), 9(2) 99-115

[36] Makreski P., Jovanovski G., Kaitner B., "Minerals from Macedonia. XXIV. Spectra-structure characterization of tectosilicates. Journal of Molecular Structure" Journal of Molecular Structure, 924-926, 413-419, 2009

[37] Jovanovski G., Makreski P., Kaitner B., Boev B., "Silicate Minerals from Macedonia. Complementary Use of Vibrational Spectroscopy and X-ray Powder Diffraction for Identification and Detection Purposes" Croatica Chemica Acta, 82 (2), 363-386, 2009

[38] Hofmeister A. M., Chopelas A., "Vibrational Spectroscopy of End-Member Silicate Garnets" Physics and Chemistry of Minerals, 17 (6), 503-526, 1991

[39] Mingsheng P., Mao H. K., Dien L., Chao E. C. T., "Raman spectroscopy of garnet-group minerals" Chinese Journal of Geochemistry, 13 (2), 176-183, 1994

[40] Kolesov B. A., Geiger C. A., "Raman spectra of silicate garnets" Physics and Chemistry of Minerals, 25 (2), $142-151,1998$

[41] Moroz T., Ragozin A., Salikhov D., Belikova G., Puchkov V., Kagi H., "Micro-Raman spectra of ugrandite garnet" Spectrochimica Acta Part A: Molecular and Biomolecular Spectroscopy, 73 (3), 436-439, 2009

[42] Bersani D., Andò S., Vignola P., Moltifiori G., Marino I.-G., Lottici P. P., Diella V., "Micro-Raman spectroscopy as a routine tool for garnet analysis" Spectrochimica Acta Part A: Molecular and Biomolecular Spectroscopy, 73 (3), 484-491, 2009

[43] Tlili A., Smith D. C., Beny J.-M., Boyer H., “A Raman microprobe study of natural micas” Mineralogical Magazine, 53 (370), 165-179, 1989

[44] McKeown D. A., Bell M. I., Etz E. S., "Vibrational analysis of the trioctahedral mica phlogopite" American Mineralogist, 84 (5-6), 970-976, 1999

[45] McKeown D. A., Bell M. I., Etz E. S., "Vibrational analysis of the dioctahedral mica: $2 M_{1}$ muscovite" American Mineralogist, 84 (7-8), 1041-1048. 1999

[46] Wang A., Freeman J., Kuebler K. E. "Raman spectroscopic characterization of phyllosilicates" The 33 $3^{\text {rd }}$ Lunar and Planetary Science Conference, March 11-15, Proceedings, \#1374, League City, Texas, 2002

[47] Gasharova B., Mihailova B., Konstantinov, L., "Raman spectra on various types of tourmaline" European Journal of Mineralogy, 9 (5), 935-940, 1997

[48] McKeown D. A., "Raman spectroscopy, vibrational analysis, and heating of buergerite tourmaline" Physics and Chemistry of Minerals, 35 (5), 259-270, 2008

[49] Hoang L. H., Hien N. T. M., Chen X. B., Minh N. V., Yang I. S., "Raman spectroscopic study various types of tourmalines" Journal of Raman Spectroscopy, 42 (6), 1442-1446, 2011

[50] Kuebler K., Wang A., Freeman J. J., Jolliff B. L., "Database of Raman mineral spectra for planetary surface exploration" The $37^{\text {th }}$ Lunar and Planetary Science Conference, March 13-17, Proceedings, \#1907, League City, Texas, 2006

[51] Best M. G., "Igneous and Metamorphic Petrology" 2nd Ed., Blackwell Publishing, Oxford, UK, 729s, 2003

[52] Dempster T. J., "Garnet zoning and metamorphism of the Barrovian Type Area, Scotland" Contributions to Mineralogy and Petrology, 89 (1), 30-38, 1985

[53] Snelling A. A., "Regional Metamorphism within a Creationist Framework: What Garnet Compositions Reveal" Answers in Depth, 5, 198-208, 2010 